УДК 338.24

DOI: $10.14451 / 1.197 .198$

\title{
ТРАНСФОРМАЦИЯ ВИП-СЕГМЕНТА ПОТРЕБИТЕЛЕЙ БАНКОВСКИХ УСЛУГ В КОНТЕКСТЕ ЦИФРОВИЗАЦИИ ЭКОНОМИКИ
}

\author{
() 2021 Терентьева Дарья Андреевна \\ магистрант \\ Санкт-Петербургский государственный университет, Россия, Санкт-Петербург \\ E-mail: dulybina@mail.ru \\ (C) 2021 Ершова Алёна Викторовна \\ аспирант кафедры маркетинга \\ Санкт-Петербургский государственный экономический университет, Россия, Санкт-Петербург \\ E-mail: alena.tsyura@mail.ru
}

Цифровизация всех аспектов жизнедеятельности человека на данный момент является повсеместной. Следствием данного процесса является формирование уникальных информационных массивов, описывающих как специфику процесса потребления той или иной цифровой услуги, так и специфику потребителя данной услуги. Анализ данных информационных массивов позволяет формировать уникальные свойства потребляемой услуги, ориентированные на конкретного потребителя. Описанная специфика наиболее значимо проявляется в сфере банковских услуг. Авторы в своей статье «Системный анализ привлекательности банков для представителей ВИП-сегмента потребителей в рамках цифровой информационной среды» [6] предложили инструмент, позволяющий оценить привлекательность банка для представителей ВИП-сегмента потребителей, исключительно на основе анализа информационного фона банка. В рамках данной статьи приводится критика данного инструментария и формулируются основные направления его развития.

Ключевые слова: системный анализ, банк, ВИП-сегмент потребителей, цифровизация.

Цифровизация стала неотъемлемой частью действительности 21 века, представляя собой социально-экономическую трансформацию, инициированную массовым внедрением и усвоением цифровых технологий, т.е. технологий создания, обработки, обмена и передачи информации [1].

Процесс цифровизации является технологическим трендом, который воздействует на все сферы жизни человека и общества. Трансформация функционирующих на данный момент процессов экономического сектора в цифровые аналоги приводит к повышению динамичности экономики как таковой [2]. Цифровая экономика предполагает тотальную глобализацию, создает сверхвысокую конкурентную среду, обеспечивает новое качество жизни, бизнеса и государственных услуг [3].

Технологическое развитие меняет общество, экономику, и банковскую систему в частности, которая является одним из ключевых институтов страны [4]. С течением времени облачные приложения, большие данные и концепция понимания чтения больших данных приобрели важное значение. Развитие цифровой коммуникации позволило общаться с людьми по всему миру. С самого начала цифровое банковское обслуживание приобрело форму канала распространения, что обеспечило легкость доступа и преимущества с точки зрения затрат наряду с ростом производительности, позволив предоставлять банковские услуги без персонала. Социальные сети, такие как Twitter, Facebook и Linkedin, активизировали интерактивное общение в Интернете, что привело к появлению новых бизнес-моделей, основанных на социальных сетях. Банки прогрессируют, становясь институтами, преобразующими данные в информацию и маркетинговую информацию, а не в деньги. Цифровые изменения направляют нашу банковскую точку зрения, ориентированную на банк, к точке зрения, ориентированной на клиента, в постоянно растущей модели [5].

В данной работе приводятся результаты проведенного ранее исследования о привлекательности банков для представителей ВИП-сегмента потребителей банковских услуг в контексте цифровой среды [6]. Авторы более детально 
с точки зрения применения рассматривают построенный ранее аналитический инструмент для сравнительного анализа трех коэффициентов, отражающих уровень привлекательности банка для потребителя, а именно: коэффициент надежности, коэффициент инновационной ассоциативности и коэффициент тональной совместимости. Данная статья является логическим продолжением упомянутой выше работы и предлагает дальнейшие пути развития полученного инструмента, который может использоваться как для других сегментов потребителей непосредственно банковского сектора, так и в совершенно иных областях, где цифровая среда играет ключевую роль.

Проблема, которую решают авторы данной работы, заключается в определении уровня привлекательности банковских компаний относительно друг друга в контексте потребления клиентов ВИП-категории. Данная проблема действительно актуальна, так как процесс цифровизации значительным образом повлиял на экономику в целом, и банковский сектор в частности. Очень важно сформировать инструмент и разработать стратегии его использования, позволяющие оценить относительную привлекательность банковских компаний, благодаря чему потребитель сможет оптимизировать процесс принятия решения и осуществить осознанный выбор в поддержку лучших услуг одной из самых значительных отраслей экономики.

Цель исследования заключается в том, чтобы построить аналитический инструмент для сравнительного анализа привлекательности банка через призму ВИП-сегмента потребления и предложить варианты его использования.

Методология формирования аналитического инструмента напрямую связана с аватаром представителей ВИП-сегмента, который был проанализирован авторами ранее в статье [7]. На основании проведенного исследования были выделены следующие свойства представителей ВИП-сегмента потребителей банковских услуг:

1. Центрирование надежности взаимодействия как ключевой характеристики банковской организации. В данном случае под надежностью взаимодействия можно понимать способность банка сохранять во времени в установленных пределах значения всех параметров, характеризующих оказываемые услуги [8]. Данное свойство играет немаловажную роль в контексте рассматриваемого сегмента потребителей, так как отсутствие систематизированных представляемых услуг или снижение качества взаимодействия между банком и ВИП-клиентом может повлечь необратимые репутационные потери, которые в свою очередь приведут к финансовым.

2. Совместимость восприятия. Данное свойство отражает минимизацию противоречий между медиа-восприятием банка основными потребителями, а также самих потребителей услуг данного банка, медиа-восприятием как представителя ВИП-сегмента, так и его возможного бизнеса и/или окружения. Данное свойство является крайне дискуссионным с точки зрения оценки, однако одними из наиболее возможных параметров квантификации данного свойства являются тональная и лексическая корреляция.

3. Инновационная активность. В результате процесса цифровизации, который затронул многие сферы экономики, в категории услуг появились такие критерии как относительная инновационность оказываемых услуг и динамика развития относительной инновационности оказываемых услуг.

В соответствии с выделенными свойствами, присущими именно данной категории потребителей, был разработан аналитический инструмент и рассмотрены коэффициенты, характеризующие данные свойства.

Одной из особенностей цифровой среды является формирование образа компании в глазах потребителя, в связи с чем для целей квантификации каждого из свойств необходимо использовать исключительно открытые данные цифровой информационной среды, в первую очередь представленные в форме естественной информации.

Первое свойство, а именно надежность взаимодействия банка и клиента, носит реверсивный характер в контексте психологии. Следовательно, определение надежности системы заключается в отсутствии информационной компоненты, описывающей различные сбои работы банка. Так как информация о каких-либо неполадках системы формирует у всех групп потребителей, в частности у ВИП-сегмента, образ ненадежного банка, она не может содержаться на официальных источниках. Авторы анализируют общий информационный фон, акцентируя внимание на новостном потоке. Параметр, характеризующий вышеописанное свойство, может быть на- 
зван коэффициентом надежности, и рассчитан следующим образом:

$$
K R_{i}=\frac{1}{F_{n \cdot g_{\cdot i}}+1}
$$

Где:

1. $K R_{i}-$ коэффициент надежности банка $\mathrm{i}$ за исследуемый период;

2. $F_{n . g . i}-$ число новостных единиц о банке I, содержащих как минимум один из выделенных ранее токенов, за исследуемый период.

Процесс калькуляции данного коэффициента может быть автоматизирован средствами языка программирования Python 3. Данные расчеты могут быть осуществлены в 4 этапа, которые представлены ниже.

Этап 1 - Парсинг массива новостей относительно исследуемого банка. На данном этапе осуществляется автоматизированный сбор информации относительно исследуемых банков. Поскольку искомый коэффициент носит относительный характер, для принятия управленческих решений его необходимо сравнивать либо со среднерыночным значением, либо с показателями других компаний. Для целей автоматизации поиска и агрегирования новостной информации авторы используют библиотеку pygooglenews [9].

Этап 2 - Токенизация массива новостей относительно исследуемого банка. В рамках данного этапа производится трансформация полученных ранее новостных заголовков в списки токенов. Данный этап предполагает следующие подэтапы:

1. Исключение из полученных ранее новостных заголовков знаков пунктуации.

2. Трансформация заглавных форм.

3. Первичная токенизация, предполагающая трансформацию единых новостных заголовков в списки последовательных лексем (токенов).

4. Лемматизация полученных токенов, для целей формирования списков, содержащих исключительно лексемы в базовой словарной форме.

5. Исключение из списков лемматизированных токенов лексем с низкой содержатеной значимостью (предлогов, союзов, местоимений и т.д.)

Этап 3 - Идентификация новостей, содержащих как минимум один из токенов, обратно ассоциирующиеся с надежности взаимодействия с банком. Результатом реализации данного этапа является список, содержащий введенное ранее число новостных единиц, содержащих как минимум один из соответствующих токенов, для каждого из исследуемых банков за исследуемый период (календарный год).

Этап 4-Расчет и нормализация коэффициента надежности. На данном этапе осуществляется инвертирование и нормализация полученных на предыдущем этапе значений. Результатом данного этапа является список нормализованных коэффициентов надежности для каждого из исследуемых банков. Данный коэффициент может использоваться для проведения сравнительного анализа и принятия управленческих решений.

Далее авторы рассматривают свойство совместимости восприятия банка. Содержательная составляющая данного свойства является единообразной для многих банковских компаний, что связано со спектром предоставляемых услуг, поэтому авторы акцентируют внимание на эмоциональном восприятии банка. Это может быть осуществлено при помощи оценки тональности текста [10]. Для оценки эмоционального восприятия потребителей именно ВИП-сегмента авторы выделили следующие уровни: уровень нейтральности, уровень позитивности, уровень негативности, уровень лексической упрощенности и уровень средовой единообразности. В соответствии с результатами исследования [7] аватар представителя ВИП-сегмента потребителей банковских услуг склонен отдавать предпочтение банкам, характеризующимся максимальным значением следующего соотношения тональных компонент:

$$
K T_{i}=\frac{\overline{T_{\text {neutral }_{i}}}+\overline{T_{\text {skip }_{i}}}}{\overline{{\overline{\text { posiive }_{i}}}_{\text {ingative }}}+\overline{T_{\text {npeech }_{i}}}}
$$

Где:

1. $K T_{i}-$ коэффициент тональной совместимости банка і за исследуемый период;

2. $\overline{T_{\text {neutral }}}-$ средний уровень нейтральности анализируемого контента, представляющего банк i, за исследуемый период;

3. $\overline{T_{\text {skip }}}$ - средний уровень средовой единообразности анализируемого контента, представляющего банк i, за исследуемый период;

4. $\overline{\text { posive }_{i}}-$ средний уровень позитивности 
анализируемого контента, представляющего банк i, за исследуемый период;

5. $\overline{T_{\text {negative }}}-$ средний уровень негативности анализируемого контента, представляющего банк i, за исследуемый период;

6. $\overline{T_{\text {speech }_{i}}}$ - средний уровень лексической упрощенности анализируемого контента, представляющего банк і, за исследуемый период.

Алгоритм калькуляции коэффициента тональной совместимости может быть представлен следующим последовательными этапами.

Этап 1 - Парсинг идентификаторов записей из официального сообщества банка в социальной сети. В качестве анализируемой социальной сети в рамках данного исследования авторы используют «ВКонтакте». Результатом реализации данного этапа является сложный массив, состоящий из ключей в форме наименований банков, и значений, сохраненных в данных ключах, в форме списков идентификаторов записей из официальных сообществ анализируемых банков в социальной сети «ВКонтакте».

Этап 2 - Парсинг комментариев пользователей к записям из официального сообщества банка в социальной сети. Результатом реализации данного этапа является структурированный массив комментарием, определенный для каждого анализируемого банка.

Этап 3 - Оценка тональности комментариев пользователей к записям из официального сообщества банка в социальной сети. Для целей реализации данного этапа используется специализированная библиотека инструментов оценки тональности текстов на русском языке «Dostoevsky». По результатам реализации данного этапа формируется массив данных, содержащий усредненные значения необходимых тональных компонент комментариев к постам в официальных сообществах анализируемых банков.

Эman 4 - Расчет коэффициента тональной совместимости. Коэффициент тональной совместимости калькулируется для каждого из анализируемых банков. По результатам реализации данного этапа формируется список коэффициентов тональной совместимости для каждого из исследуемых банков.

Значения данного коэффициента могут быть использованы для сравнительного анализа и дальнейшего принятия управленческих решений. В совокупности с коэффициентом надежности, коэффициент тональной совместимости формирует условно-традиционный ценностносравнительный аналитический результат для представителей ВИП-сегмента потребителей банковских услуг.

Однако в контексте процесса цифровизации коэффициент, характеризующий инновационную активность приобретает большее значение. В исследовании [6] авторы квантифицируют восприятие инновационной активности банка посредством анализа общего информационного фона. Коэффициент инновационной ассоциативности, характеризующий инновационную активность рассчитывается как доля информационного фона банка, содержащая информацию относительно его инновационных достижений.

$$
K l n_{i}=\frac{F_{i n_{i}}}{F_{i}}
$$

Где:

1. $K \ln _{i}-$ коэффициент инновационной ассоциативности банка і за исследуемый период;

2. $F_{i n_{i}}$ - доля токенов, характеризующих область «Финтех» (область инновационных достижений);

3. $F_{i}$ - общая совокупность токенов, описывающих информационный фон банка і за исследуемый период.

Для целей автоматизированной калькуляции коэффициента инновационной ассоциативности банка может быть использован алгоритм, приведенный ниже.

Этап 1 - Парсинг информации, актуально характеризующей область «Финтех». По результатам данного этапа формируется список, содержащий текст постов, посвященных области «Финтех».

Эman 2 - Токеннизация информации, актуально характеризующей область «Финтех». По результатам данного этапа формируется массив данных, содержащий как сами токены, характеризующие область «Финтех», так и их частоту, необходимую для определения удельного веса каждого токена.

Этап 3 - Парсинг информации, актуально описывающей информационный фон анализируемого банка. По результатам реализации данного этапа формируется аналитическая матрица, содержащая посты со стены официального сообщества анализируемого банка в социальной сети.

Эman 4 - Токеннизация информации, актуально описывающей информационный фон ана- 
лизируемого банка. По результатам токенизации формируется массив данных, содержащий как сами токены, описывающие информационный фон анализируемого банка, так и их частоту, необходимую для определения удельного веса каждого токена.

Этап 5 - Расчет коэффициента инновационной ассоциативности банка. По результатам калькулирования формируется массив коэффициентов инновационной ассоциативности, соответствующих анализируемым банкам.

Для комплексного сравнительного анализа необходимо использовать каждый из предложенных коэффициентов. На основании полученных данных может быть проведен конкурентный анализ, а также приняты различные управленческие решения.

С точки зрения производства и потребления цифровизация экономики носит дифференцированный характер и оказывает воздействие на большинство направлений. Так, в контексте потребления можно выделить 4 ключевых темы, которые внесут новую ценность для отрасли и общества в целом:

1. Поток данных о потребителях и получение ценности;

2. Экономика опыта;

3. Многоканальная розничная торговля;

4. Цифровая Операционная модель.

Цифровизация помогает компаниям использовать потребительские данные для инноваций и улучшения качества обслуживания клиентов. Растущая важность данных привлечет повышенное внимание и активизацию со стороны потребителей и регулирующих органов, поскольку общество придает еще большее значение конфиденциальности и прозрачности данных.

Продукты превратятся в услуги, а услуги в опыт, и данные станут основой их доставки. Гиперперсонализация создает новые модели доходов в среде, где доходы более тесно связаны с результатами для отдельных людей и общества. Данная тенденция приводит к необходимости акцентировать внимание на таком аспекте как надежность взаимодействия между компанией, предоставляющей услуги, и потребителем. Так, возникает потребность в оценке качественного взаимодействия, формирующего паттерн потребительского поведения в различных сегментах.

С ростом онлайн-покупок в большинстве категорий традиционные предприятия долж- ны меняться, чтобы оставаться актуальными. Многоканальные стратегии будут играть важную роль. Компании, производящие потребительские товары, также будут нуждаться в эффективных стратегиях для конкуренции в электронной торговле и получения прибыли в экономике совместного использования. Соответственно, возникает потребность в новом подходе к конкурентному анализу, рассматривающему, в частности, цифровую информационную среду и включающему в себя сформированный потребителем образ компаний.

Интеллектуальные цепочки поставок и заводы позволят массово настраивать продукты и использовать многоканальный опыт. Способность фирмы управлять потребительским опытом будет иметь решающее значение для получения конкурентного преимущества. Для реализации возможности управления потребительским опытом, необходимо учитывать эмоциональную составляющую отношения к различного рода услугам для повышения конкурентоспособности в контексте цифровой среды и не только.

Цифровизация потребительских отраслей может высвободить более 10 триллионов долларов в промышленности и общественной ценности в течение следующего десятилетия. Ожидается, что электронная коммерция будет во многом определять общественную ценность.

Более широкое проникновение электронной коммерции меняет розничный ландшафт, передавая ценовую власть от производителей интернет-ритейлерам. Это также выравнивает игровое поле, помогая более мелким и нишевым игрокам конкурировать с доминирующими крупными брендами. Электронная коммерция имеет потенциальное влияние на общество в размере 2,7 трлн. долларов, поскольку она сокращает время поездок на работу более чем на 250 миллионов часов и предоставляет доступ к более широкому спектру продуктов и более низким ценам. В2В и трансграничные платформы могут еще больше усилить влияние электронной коммерции на общество [11].

Пандемия COVID-19 повлияла на экономическую и социальную жизнь. Изучение экономических потрясений, вызванных пандемией, основано на междисциплинарном подходе, включающем использование методов общественного здравоохранения, психологии, классической экономики, поведенческой экономики, институциональной экономики, систем- 
ного анализа. Такие пандемические потрясения отличаются от ранее известных экономических потрясений. Содержание и силы потрясений, связанных с пандемией, представляют собой смесь естественного события и результатов профилактических государственных мер. Экономические потрясения были определены следующим образом: внешние потрясения, потрясения спроса и предложения, трансграничные побочные эффекты пандемических экономических потрясений рассматриваются в качестве основной причины замедления национальной, региональной и мировой экономики [12].

Пандемия COVID19 значительно повлияла на трансформацию бизнес-процессов и цифровизацию экономики в целом для целого ряда предприятий с направлениями и В2B, и В2С.

Банковский сектор представляет собой один из многих секторов экономики, претерпевших значительные изменения. Трансформации подверглись как внутренние экономические процессы, так и взаимодействие с потребителем. В связи с этим появилась необходимость в оценке образа банковских компаний именно в контексте цифровой среды, так как во время пандемии большая часть потребительской активности перешла в онлайн-формат, как и многие другие аспекты общественной жизни. Если раньше потребитель составлял для себя образ компании исходя из множества различных критериев, то в условиях ограниченной действительности и значительного увеличения доли цифрового окружения, ситуация кардинально изменилась. Что приводит к необходимости пересмотреть подход к оценке привлекательности компаний банковского сектора.

Для различной аналитической деятельности, в частности при анализе контрагентов, кредитных портфелей, активности офисов, банки используют Business Intelligence (BI) системы. Данные системы могут быть дополнены аналитическими данными, собранными в режиме реального времени и используемыми для прогнозных показателей. Такие технологии обработки больших данных помогают сформировать различные программы лояльности и персональные предложения для клиента.

Другим трендом технологического аспекта является онлайн банкинг, который приходит на замену CRM системам. В данной ситуации клиент получает возможность управления собственными средствами и разрешенными опера- циями без сотрудников банка. Возможности онлайн банкинга расширяются за счет увеличения количества адресатов платежей, а также за счет дополнительных сервисов. Доступ потребителей к системе онлайн банкинга предусмотрен также через мобильные приложения, разработанные специально под данную систему для возможности использования мобильных устройств.

Также одним из направлений технологического развития банковского сектора являются системы электронных платежей на основе биометрической идентификации при помощи мобильных устройств. В качестве примера могут быть рассмотрены ApplePay, SamsungPay. Аналитики Tadviser отмечают перспективу поддержки картами «Мир» совершения оплат по технологиям Apple Pay и Samsung Pay. Безопасность финансовых транзакций постоянно находится в фокусе деятельности банков. Существует тенденция к использованию мобильных устройств клиентов как средств для биометрической идентификации (отпечатки пальцев распознаются смартфонами, лицо человека распознается веб-камерой или камерой мобильного устройства).

Упрощение процедуры идентификации клиента при помощи голоса или на основе биометрических данных является одной из важных задач финансового сектора. Это связано с увеличением уровня удобства использования услуг, а соответственно и с привлечением клиентов. Использование чат ботов и голосовых помощников находит распространение среди российских банков. Данные системы позволяют решать часть вопросов клиента без участия сотрудника банка.

Финансовые инвестиции развиваются в направление повышения уровня использования данных сервисов с акцентом на доступности информации и удобстве использования. Главный аспект развития - персонализированный продукт, который удобнее приобрести онлайн.

Технология блокчейн осваивается российскими банками. Например, Росевробанк в партнерстве с Microsoft на основе инфраструктуры Ethereum Consortium Blockchain предложил идентификацию клиента через приложения любым другим банком, который обменяется данными с Росевробанком для определения статуса и идентификации клиента. Таким образом, открываются перспективы получения клиентом услуг разных банков в одном месте (в одном 
приложении) по принципу одного окна.

Любые контрагенты в дальнейшем могут существенно сэкономить на процессах подготовки и осуществления сложных сделок за счет контроля и взаимодействия умных контрактов, действующих на блокчейн платформе, доверие к которой гарантируется банком, выступающим также гарантом сделок [13].

Данные трансформации привели к изменениям паттернов потребительского поведения и изменению аватаров основных потребителей банковских услуг. Данное воздействие затронуло все группы потребителей, в том числе значительную для банковского сектора консервативную группу ВИП-сегмента [7]. В связи с чем появилась необходимость пересмотреть формирование образа банковских компаний у потребителя в контексте цифровой среды, а также скорректировать оценку привлекательности компаний, учитывая произошедшие изменения.

Предложенный авторами аналитический инструмент позволяет провести сравнительный анализ банков по трем различным критериям, характеризующим образ компании в цифровой информационной среде для потребителей ВИП-сегмента. В контексте процесса цифровизации, а также под воздействием пандемии COVID-19, многие процессы, сервисы и услуги переместились в онлайн-среду. Данная тенденция послужила причиной трансформации уже сформированных паттернов взаимодействия между банковскими компаниями и клиентами, что в свою очередь привело к необходимости создания соответственного аналитического инструмента.

В рамках повышенной конкуренции и персонализированного подхода необходимо учитывать такие составляющие как надежность и качество взаимодействия между банком и клиентом, а также эмоциональную компоненту со стороны потребителя, формирующую образ компании в цифровой среде. Повышенная конкуренция обусловлена увеличением скорости реализации различных процессов в электронной форме, а также внедрением инноваций. Именно поэтому предложенная авторами модель сравнительной оценки привлекательности банков полностью соответствует запросу потребителя: в ней оценивается надежность взаимодействия, инновационная активность, а также эмоциональная составляющая в контексте образа компании.

Полученные ранее результаты [6], позволя- ют провести не только сравнительный анализ и сделать выводы о наиболее привлекательном банке для ВИП-сегмента потребителей, но также сформулировать управленческие решения, направленные на повышение конкурентоспособности и разработку стратегии продвижения в контексте цифровой информационной среды.

Данный инструмент может быть расширен и дополнен иными коэффициентами в зависимости от анализируемой категории потребителей, которая может быть охарактеризована отличными от рассмотренных в данной работе свойствами, разработанными на базе аватара ВИП-сегмента [7].

В условиях цифровизации многие аспекты экономической деятельности подвергаются определенным изменениям, в связи с чем возникает вопрос, как оценить привлекательность различных компаний и сохранить лояльных клиентов, формирующих постоянный значительный сегмент потребления предлагаемых компанией услуг. В данной работе рассматривается банковский сектор и ВИП-сегмент потребления, на основании аватара которого строится аналитический инструмент оценки привлекательности банковской компании в контексте сравнения с конкурентами.

Данная работа является актуальной, так как на данный момент процесс цифровизации значительно трансформирует многие аспекты экономики, в частности банковский сектор. Это приводит к большей доступности информации о различных компаниях, на основании которой ВИП-клиенты, формирующие значительный сегмент среди потребителей банковский услуг, могут принимать решения о смене компании. Данная ситуация может основательно повлиять на потребительскую базу множества банковских компаний, и своевременная оценка при помощи предложенного авторами алгоритма позволит выявить слабые стороны и предпринять меры по удержанию лояльных клиентов ВИП-сегмента.

Основным ограничением данного исследования является необходимость использования построенного аналитического инструмента только для сравнительного анализа. Таким образом, данная методология позволяет выявить наиболее привлекательный банк с учетом особенностей потребителей ВИП-сегмента, но не отразить абсолютный уровень привлекательности. Кроме того, в рассмотренной конфигурации 
аналитического инструмента были проанализированы заголовки в новостных источниках, в то время как более глубокая и детальная информация относительно привлекательности банковской компании может содержаться внутри текстового материала.

Предложенный авторами аналитический инструмент представляет интерес как для клиента банка, так и для самой компании. Данный инструмент может широко применяться для анализа со стороны потенциального клиента для совершения выбора в пользу наиболее конкурентоспособного и привлекательного банка. Также данный алгоритм может быть использован самим банком для внутреннего аудита и выявления слабых сторон функционирующей системы для дальнейшего ее совершенствования. Кроме того, аналитический инструмент может быть использован банком в качестве маркетингового средства для завоевания доверия потенциального потребителя ВИП-сегмента путем демонстрации «прозрачности» собственной деятельности и акцентирования внимания на аспекте доверия.

В качестве дальнейшего исследования авторы могут акцентировать внимание на других сегментах потребителей банковских услуг и сформировать аналитические инструменты для детального анализа каждой группы потребителей.

\section{Библиографический список}

1. Katz R. The Transformative Economic Impact of Digital Technology // The United Nations Commission On Science And Technology For Development. 2015. № May.

2. Lang V. Digitalization and Digital Transformation. 2021. P. 1-50.

3. Ohrimenco S., Borta G. THE NATURE OF SHADOW DIGITAL ECONOMICS // MEST J. 2021. Vol. 9. P. 146-156.

4. Банковский сектор // Экономическое развитие России. 2016. Vol. 23, № 1.

5. Impacts of Digitalization on Banks and Banking. 2021. P. 33-50.

6. Ершова A.B. et al. Системный анализ привлекательности банков для представителей ВИП-сегмента потребителей в рамках цифровой информационной среды // Экономические Науки. 2021. № 194.

7. Ершова А.В., Шубаева В.Г.Применение теории аватаров в банковском маркетинге вип-сегмента // Экономические науки. 2020. № 193.

8. Евгеньева А.П. (ред.. Словарь русского языка в четырех томах. Москва: РАН, Ин-т лингвистич. исследований, 1999. $736 \mathrm{p}$.

9. Pygooglenews [Electronic resource]. URL: https://github.com/kotartemiy/pygooglenews (accessed: 25.04.2021).

10. Что такое тональность текста и каким образом ее создать // Блог Думай и пиши [Electronic resource]. URL: https://writingfor.online/post/tonalnost-teksta/ (accessed: 19.04.2021).

11. Accenture. Digital Transformation Initiative In collaboration with Accenture for Business and Society. 2017. № Enero. P. 1-71.

12. Shevchenko V. ECONOMIC SHOCKS OF THE PANDEMIC IMPACT: THE EUROPEAN CASE // Three Seas Econ. J. 2020. Vol. 1. P. 53-59.

13. Медовников Д. С. Цифровая экономика: глобальные тренды и практика российского бизнеса. 2017. 121 p. 